\title{
EARLY EXTUBATION AND CPAP USE IN INFANTS BORN UNDER 1000 GRAMS; INSTITUTIONAL EXPERIENCE
}

\author{
J. Alallah, M. Al-Qurashi, S. Elbeely, A. Moustafa, A. Musba, E. Hanafi \\ Departement of Pediatrics, King Khalid National Guard Hospital, Jeddah, Saudi Arabia
}

Background: Prolonged mechanical ventilation of ELBW infants $(<1000 \mathrm{~g})$ is associated with increased rates of bronchopulmonary dysplasia (BPD).currently Nasal CPAP is widely used It is established as an effective method of preventing Extubation failure and in the management of apnea of prematurity.

Objective: To determine the trends in early CPAP use $\&$ its impact on outcomes of babies $</=1000 \mathrm{gm}$.

Design and methods: Records of all ELBW admitted NICU at King Abdulaziz Medical City, WR,SA from Jan2007 to Dec2010, were collected. outcome was the success rate of early extubation in ELBW infants who were intubated at delivery, extubated in the first $48 \mathrm{hrs}$ and did not require re-intubation within 7 days following extubation. Secondary outcomes included short term morbidities.

Result: During the 4 years study period, Sixty ELBW infants were included. Forty one (68\%) babies survived till hospital discharge. The mean BW was 828. $\mathrm{g}(+/-116.8 \mathrm{SD})$; the mean GA was 26.9 weeks (+/1.97). 28 of 38 were extubated early (74\%), 3 babies never been intubated; of these,28/28 (100\%) had a successful extubation. Infants extubated early had a higher mean birth weight (859 vs716 g, $<<0.0001)$ and gestational age ( 27 vs25.6 weeks, $\mathrm{p}<0.0001)$. Also had lower rate of morbidities compared to those who remained ventilated after 48 hours. grade $3-4$ IVH or PVL 0 Vs $20 \%$ surgical PDA 7\% vs. 25 and CLD 7\% vs. $30 \%$.as well as shorter hospital stay 72 days Vs 84 days.

Conclusion: Early extubation was associated with improved outcomes in ELBW infants. 